\title{
Melatonin and Its Role in Lower Urinary Tract Function: An Article Review
}

\author{
Ali Fathollahi Firouz Daneshgari Ann T. Hanna-Mitchell \\ Urology Institute, Case Western Reserve University, Cleveland, $\mathrm{OH}$., USA
}

\section{Key Words}

Melatonin • Bladder dysfunction • Inflammation • Antioxidant • Aging

\begin{abstract}
This article reviewed the results of studies done on animals that assessed effects of melatonin on bladder function. Melatonin does not change strip relaxation on its own. However, pretreatment with melatonin decreases contractile responses induced by phenylephrine, acetylcholine, bethanechol and $\mathrm{KCl}$ in a dose-dependent manner. The contractile responses induced by the direct calcium channel openers are significantly decreased by melatonin pretreatment. It also binds to $\mathrm{Ca}^{2+}$-activated calmodulin, and prevents it from activating myosin light-chain kinase. It may have direct effects on ion channels which are responsible for regulating bladder contraction. Its other mode of action on bladder occurs via the brain $\mathrm{GABA}_{A}$ receptor. Melatonin is an antioxidant. In bladder, treatment with melatonin prevents elevations in malondialdehyde levels, reverses changes in glutathione levels, and decreases myeloperoxidase levels compared with oxidative injury. It can normalize age induced bladder dysfunction through its antioxidant effects, inhibiting smooth muscle contractility directly and restoring impaired contractility via normalization of $\mathrm{Ca}^{2+}$ handling and sensitizations pathways. It attenuates the severity of cystitis and inflammation. Mast cell proliferation and activation are
\end{abstract}

\section{KARGER}

Fax +4161306 1234

E-Mail karger@karger.ch

www.karger.com
(C) 2014 S. Karger AG, Basel

1015-9770/14/0083-0113\$38.00/0

Accessible online at:

www.karger.com/cur increased in cystitis, but decrease by melatonin treatment. Also, there is a decrease in expression levels of pro-inflammatory cytokines after melatonin treatment.

Copyright @ 2014 S. Karger AG, Basel

\section{Introduction}

Melatonin (N-acetyl-5-methoxytryptamine) is the major neurohormone secreted during the dark hours at night by the vertebrate pineal gland. After its formation, melatonin is released into the capillaries, and even in higher concentrations, into the cerebrospinal fluid and then spreads to most body tissues [1].

Generally, melatonin, which is the main product of the pineal gland, exerts many of its physiological actions through interaction with the membrane receptors MT1 and MT2 and intracellular proteins such as quinine reductase 2, calmodulin, calreticulin, and tubulin. Its receptors are found in the bladder as well as the prostate [2].

Melatonin may have two different effects on the vasculature, with vasoconstriction through MT1 and vasodilation through MT2 [3]. It decreases the contraction of the small and large intestines in rats, whereas it causes 
contraction of the colonic smooth muscle from guinea pig $[3,4]$. It has the ability to vasoconstrict rat caudal and cerebral arteries, and to relax porcine arterial smooth muscle $[5,6]$.

In the current review article, we reviewed the results of studies that have been done on animals, and in which they assessed the effects of melatonin on bladder function. We performed a search of the English literature through PubMed. The key words used were "bladder" and "melatonin". Our data and perspective are provided for consideration of the future direction of research.

\section{Results}

\section{Smooth Muscle Tone Adjustment}

Melatonin is shown to be involved in a variety of physiological actions, and to adjust smooth muscle tone in different tissues. In the urinary tract, both acetylcholine and $\mathrm{KCl}$ can increase the myogenic activity of bladder strips. It does not change strip relaxation and has been shown to have a little effect on the contractility on its own. However, pretreatment with melatonin decreases the contractile responses induced by phenylephrine dose-dependently. Melatonin also attenuates the peak amplitude in acetylcholine-, bethanechol- and KCl-induced contraction in a concentration dependent manner [7]. Interestingly, the inhibitory effects of melatonin on contractions are not reversible with melatonin-receptor antagonists [8]. It suggests that melatonin inhibits bladder contraction by the modulation of intracellular proteins directly.

Although as stated previously melatonin has little direct effect on muscle relaxation, it markedly potentiates the block produced by succinylcholine, implying its function as a calcium-channel blocker [9]. Many reports suggest that it has inhibitory effect on rat ileal smooth muscle, where Ca-channels seem to be necessary for inducing the inhibition [10]. Moreover, it potentiates calcium channel antagonist-induced relaxation. However, potassium channel blockers do not change melatonin activity. Furthermore, melatonin, when given prior to calcium channel openers, decreases contractile responses to a great extent [8].

Another possible mechanism by which melatonin can induce bladder inhibition may be via its interaction with calmodulin. It is shown, in other organs, that melatonin has the ability to attach to $\mathrm{Ca}^{2+}$-activated calmodulin with high affinity; the net effect will be its prevention from activating myosin light-chain kinase, which in turn will cause a decreased contractile response [11, 12]. Melatonin might have direct effects on other ion channels involved in regulating bladder contraction or changing membrane potentials which in turn affects other ion channels [11].

Melatonin has central effects on bladder function as well. Melatonin reinforces the action of the central nervous system GABAergic system [13-18]. Bicuculline, a $\mathrm{GABA}_{\mathrm{A}}$ antagonist which competes with $\mathrm{GABA}_{\mathrm{A}}$ receptor and increases the micturition reflex [19], has no significant change in bladder capacity and induces a significant increase in bladder pressure only at high doses [20]. Intracerebroventricular melatonin administration increases bladder capacity dose dependently, although it causes no significant difference in bladder contraction pressure. Bicuculline can inhibit melatonin induced increases in bladder capacity [20]. It indicates that one of melatonin actions on bladder occurs via the brain $\mathrm{GABA}_{\mathrm{A}}$ receptor, especially the GABA binding site, as direct melatonin administration to the cerebral ventricle excludes its action at the peripheral organ. Thus, melatonin is believed to suppress the micturition reflex by reinforcing brain GABAergic activity [20].

\section{Oxidative Pathway}

Free oxygen radicals have been referred to as a major cause of destruction and damage to cell membranes through lipid peroxidation. Lipid peroxidation involves degradation of polyunsaturated fatty acids of the cellular membranes. The process subsequently will result in disruption of membrane integrity. It will then lead to alterations in membrane permeability and also to increased and facilitated protein degradation, and these will eventually lead to cell lysis [21].

Melatonin is a potent free radical scavenger and antioxidant [22]. Malondialdehyde or glutathione are considered as an index of lipid peroxidation and an important part of intracellular protective mechanism against a variety of stimuli including oxidative stress [23].

In the bladder, melatonin has no effect on malondialdehyde and glutathione levels under normal circumstances; however, after oxidative damage, bladder malondialdehyde levels tend to be much higher than normal; In in vitro and in vivo experiments, melatonin has been demonstrated to have a protective effect on tissues against damage caused by a number of free radical generating agents and processes (i.e. lipopolysaccharide, kainic acid, Fenton reagents, potassium cyanide, Lcystein, excessive exercise, ischemia-reperfusion and radiation) [24-30]. The process involves reduction in lipid 
peroxidation, and scavenging the hydroxyl radical, a potentially strong initiator of lipid peroxidation, and also the peroxyl radical, which enhances lipid peroxidation in other organs $[24,25,31]$. In another process, melatonin prevents catalase inactivation by scavenging hydrochlorous acid [32]. Moreover, peroxynitrite is shown to be another molecule undergoing the scavenging effect of melatonin [33]. Treatment with melatonin before and/or after oxidative injury prevents elevations in malondialdehyde levels of bladder [34-36].

Reduced glutathione, an intracellular free radical scavenging molecule, is considered as the main component of the endogenous non-protein sulfhydryl pool [23, 37]. The exposed sulfhydryl group on these molecules enables them to protect cells by binding to a variety of potentially damaging free radicals and metabolites [38]. By maintaining the concentration of reduced glutathione, glutathione peroxidase is a critical antioxidant enzyme. Melatonin facilitates this endogenous enzyme's activity by removing hydrogen peroxide [39]. Although melatonin treatment in the rats with oxidative injury reverses the changes in glutathione levels of bladder, whether or not melatonin has a direct effect specifically on bladder via glutathione activity stimulation is yet to be further studied [35, 36, 40].

Myeloperoxidase activity is an indicator of tissue neutrophil infiltration. Neutrophil migration and activation is accompanied by the production of radical oxygen metabolites (ROM) and release of various cytotoxic proteins (e.g. proteases, myeloperoxidase and lactoferrin) which induce cellular and tissue injury. Marked myeloperoxidase activity in bladders after oxidative injury indicates that sequestered neutrophils are the main source of ROMs. Melatonin treatment decreases myeloperoxidase levels compared with oxidative injury, however, melatonin treatment in the absence of oxidative damage has no significant effect on the myeloperoxidase activity of the bladder [36].

In normal circumstances, nitric oxide (NO) produced by constitutive nitric oxide synthase (NOS) has inhibitory effects on the detrusor. It also inhibits afferent nerve activity. On the other hand, very high concentrations of NO produced by iNOS is not well tolerated and can be cytotoxic and neurotoxic [41, 42]. Chronic treatment with melatonin increases nNOS expression and decreases iNOS expression in bladder tissue. This is another feature suggesting that melatonin may have protective effects on a chronically ischemic bladder through its free radical scavenging and antioxidative properties [36].

Roles of Melatonin in Lower Urinary Tract Function
Nuclear erythroid 2-related factor 2 (Nrf2) is a transcription factor. It has a role in modification and regulation of oxidative agents and processes. It performs its regulatory role through the antioxidant response element found in the promoter region of many cytoprotective genes. Normally, Nrf2 is sequestered in the cytoplasm with an actin binding protein kelch-like ECH associated protein 1 (Keap1). Upon its activation by various processes, Nrf2 is released from Keap1, and moves into the nucleus to stimulate gene transcription [43]. The result is the upregulation of some antioxidant enzymes such as glutathione-s-transferases and superoxide dismutase, as well as redox sensitive enzymes, NADPH: quinone oxidoreductase-1, and heme oxygenase-1 (HO-1) [44]. It has been reported that Nrf2 plays an important role in modulating acute inflammatory responses by inhibiting nuclear factor-kappa B (NF- $\kappa \mathrm{B})$ activation, another molecule with similar properties [45]. Melatonin induces an increase in Nrf2 and NF- $\kappa \mathrm{B}$ factors [46].

\section{Aging}

Most common abnormalities in voiding dysfunction in the elderly include obstruction, detrusor overactivity and impaired detrusor contraction [47] manifested as increased postvoid residual urine volume, decreased micturition interval and micturition volume. Senescent animals show spontaneous contractions during the filling phase, nonvoiding contractions, implying increased contractile activity in the detrusor muscle. However, it is shown that alterations in detrusor activity could also result from changes in the central nervous system [48].

Plasma melatonin has a circadian rhythm with high levels at night, and low levels during the day, reaching peak concentrations between 02:00 and 04:00 am. Longer nights are accompanied by a longer melatonin secretion [49]. Nocturnal melatonin production is not as efficient in the elderly population and many clinical trials showed that exogenous melatonin administration restores circadian disturbances [50]. It is known that aging is partly a result of ROMs accumulation [51]. Taking that into account, melatonin deficiency and/or its secretory disturbance may have a role in the increase in oxidative damage that occurs with aging [48].

Melatonin treatment restores the changes in residual volume and detrusor overactivity that develops by aging. It may exert its effect by maintaining circadian rhythm, improvement in physiological functions or by direct actions on the bladder. There has been shown to be a decrease in nocturnal urinary frequency after melatonin administration in those elderly patients with prior noc-

Curr Urol 2014;8:113-118 
turia and bladder outlet obstruction [52]. In fact, it may reverse age induced bladder dysfunction. In vivo melatonin administration has also been demonstrated to have a protective property on the rat bladder after oxidative stress [53].

As stated previously, melatonin inhibits smooth muscle contractility directly. On a study that evaluated its effect on isolated guinea pig urinary bladder detrusor strips, and through its calcium channel blocking characteristic, melatonin was able to bind to $\mathrm{Ca}^{2+}$-activated calmodulin with high affinity, and hinder myosin light chain kinase activation. As a result, on one hand, it maintains normal bladder contractile response through its antioxidant activity, and on the other hand, decreases contractility by affecting calcium channels [7].

As aging occurs, detrusor strips will gradually lose their sensitivity to cholinergic and purinergic agonists and membrane depolarization. This insensitivity correlates with an increased level of cytoplasmic calcium concentration $\left[\mathrm{Ca}^{2+}\right]_{i}$ in response to the stimuli. Melatonin normalizes this impairment by re-adjustment of $\mathrm{Ca}^{2+}$ handling [54].

\section{Melatonin and Acute and Chronic Detrusor Overac- tivity Models}

In acute detrusor overactivity, melatonin does not significantly affect any of the urodynamic parameters. In urodynamic studies recorded in chronic detrusor overactivity, however, it is associated with an increase in intercontraction interval, increased bladder capacity, and an increase in threshold pressure [55]. These effects are due to melatonin's antioxidative function and not through its receptors because administering agomelatine, an antidepressant with melatonergic activity, deteriorates bladder dysfunction. However, this may not be the only reason behind agomelatine's action on the bladder. It may induce bladder overactivity by its $5 \mathrm{HT} 2 \mathrm{C}$ receptor antagonism. Also, peripheral melatonin administration results in more antioxidative effects without involving the receptor [55].

\section{Melatonin and Inflammation}

Inflammatory processes can enhance bladder afferent pathway activation by inducing many stimulatory molecules (cyclooxygenases, prostaglandins and nerve growth factor, etc.). Also, the presence of pro-inflammatory cytokines such as interleukin- 8 , and TNF- $\alpha$ in inflammatory processes in bladder ischemia may indicate the formation of ROS [56]. These cytokines will, in turn, induce iNOS expression [57]. So, iNOS expression is associated with bladder inflammation. Interestingly, iNOS inhibitors diminish the symptoms of cystitis. It is believed that melatonin treatment suppresses iNOS expression [58].

Melatonin treatment attenuates the severity of cyclophosphamide-induced cystitis, as shown by reducing the increase in urinary frequency and the number of low volume voids. Microscopic examination of the histological appearance with hematoxylin and eosin staining of bladders after cyclophosphamide-treatment shows extensive cystitis with significant leukocytic infiltration occuring in the submucosa. In contrast, in melatonin-treated bladders, the urothelium appears to be well preserved, and inflammatory changes in the suburothelium are mitigated. These results indicated that melatonin treatment mitigates the severity of the inflammation induced by cyclophosphamide. More specifically, mast cell proliferation and activation are significantly increased in rats with cystitis following cyclophosphamide treatment or other stresses like water avoidance [59], and are markedly decreased by melatonin treatment [58]. Also, there is a decrease in expression levels of pro-inflammatory cytokines, TNF- $\alpha$ and IL-1 $\beta$, after melatonin treatment.

There is a trend toward increasing HO- 1 expression, the rate-limiting step in heme catabolism, in the bladders of rats with cyclophosphamide pretreatment. HO-1 is considered as a negative regulator of inflammation and oxidative stress, and also has potential neuroprotective effects against oxidative injury, all of which are associated with downregulation of iNOS expression [60, 61]. Melatonin is cytoprotective by upregulating HO-1 and downregulating iNOS expression in the bladder under oxidative stress. Another marker is substance $\mathrm{P}$ which increases significantly in the spinal cord after chronic cyclophosphamide-induced cystitis, and is decreased markedly after melatonin administration. Thus substance $P$ release which increases in L6-S1 spinal cord under the condition of chronic cystitis, will decrease after melatonin treatment [58].

Similar to its previously mentioned effect on chronically overactive bladders, melatonin reduces the detrusor motor overactivity in inflamed bladders, resulting in the improvement of cystometric parameters as follow: a significant increase of intercontraction interval and functional bladder capacity, as well as a decrease of the basal pressure. Autonomic nervous system activity analysis shows sympathetic overactivity in hyperosmolar-induced overactive bladder rats, which is inhibited by melatonin treatment [62]. 


\section{Conclusion}

Although the exact mechanisms of action of melatonin on bladder function is yet to be fully understood, there is a strong body of evidence suggesting that its imbalance has a detrimental effect on bladder dysfunction.

\section{References}

1 Pandi-Perumal SR, Trakht I, Srinivasan V, Spence DW, Maestroni GJ, Zisapel N, Cardinali DP: Physiological effects of melatonin: role of melatonin receptors and signal transduction pathways. Prog Neurobiol 2008;85: 335-353.

2 Coge F, Guenin SP, Fery I, Migaud M, Devavry S, Slugocki C, Legros C, Ouvry C, Cohen W, Renault N, Nosjean O, Malpaux B, Delagrange P, Boutin JA: The end of a myth: cloning and characterization of the ovine melatonin MT(2) receptor. Br J Pharmacol 2009;158:1248-1262.

3 Harlow HJ, Weekley BL: Effect of melatonin on the force of spontaneous contractions of in vitro rat small and large intestine. J Pineal Res 1986;3:277-284.

4 Lucchelli A, Santagostino-Barbone MG, Tonini M: Investigation into the contractile response of melatonin in the guinea pig isolated proximal colon: the role of 5-HT4 and melatonin receptors. Br J Pharmacol 1997;121: $1775-1778$

5 Regrigny O, Delagrange P, Scalbert E, Lartaud-Idjouadiene I, Atkinson J, Chillon JM: Effects of melatonin on rat pial arteriolar diameter in vivo. Br J Pharmacol 1999;127: 1666-1670.

6 Geary GG, Duckles SP, Krause DN: Effect of melatonin in the rat tail artery: role $\mathrm{K}+$ channels and endothelial factors. Br J Pharmacol 1998;123:1533-1540.

7 Semerciöz A, Onur R, Ayar A, Orhan I: The inhibitory role of melatonin on isolated guinea-pig urinary bladder: an endogenous hormone effect. BJU Int 2004; 94:1373-1376.
8 Han JH, Chang IH, Myung SC, Lee MY, Kim WY, Lee SY, Lee SY, Lee SW, Kim KD: A novel pathway underlying the inhibitory effects of melatonin on isolated rat urinary bladder contraction. Korean J Physiol Pharmacol 2012;16:37-42.

9 Uchida K, Aoki T, Satoh H, Tajiri O: Effects of melatonin on muscle contractility and neuromuscular blockade produced by muscle relaxants. Masui 1997;46:205-212.

10 Reyes-Vazquez C, Naranjo-Rodriguez EB, Garcia-Segoviano JA, Trujillo-Santana JT, Prieto-Gomez B: Apamin blocks the direct relaxant effect of melatonin on rat ileal smooth muscle. J Pineal Res 1997;22:1-8.

11 Ayar A, Kutlu S, Yilmaz B, Kelestimur H: Melatonin inhibits spontaneous and oxytocin-induced contractions of rat myometrium in vitro. Neuro Endocrinol Lett 2001;22:199_ 207.

12 Ouyang H, Vogel HJ: Melatonin and serotonin interactions with calmodulin: NMR, spectroscopic and biochemical studies. Biochim Biophys Acta 1998;1383:37-47.

$13 \mathrm{Xu}$ F, Li JC, Ma KC, Wang M: Effect of melatonin on hypothalamic gamma-aminobutyric acid, aspartic acid, glutamic acid, beta-endorphin and serotonin levels in male mice. Biol Signals 1995;4:225-231.

14 Rosenstein RE, Cardinali DP: Melatonin increases in vivo GABA accumulation in rat hypothalamus, cerebellum, cerebral cortex and pineal gland. Brain Res 1986;398:403406.
15 Rosenstein RE, Estévez AG, Cardinali DP: Time-dependent effect of glutamic acid decarboxylase activity and CI influx in rat hypothalamus. J Neuroendocrinol 1989;1:443447

$16 \mathrm{Wu}$ FS, Yang YC, Tsai JJ: Melatonin potentiates the GABA (A) receptor-mediated current in cultured chick spinal cord neurons. Neurosci Lett 1999;260:177-180.

17 Coloma FM, Niles LP: Melatonin enhancement of $[3 \mathrm{H}]$-gamma-aminobutyric acid $[3 \mathrm{H}]$ muscimol binding in rat brain. Biochem Pharmacol 1988;37:1271-1274.

18 Stankov B, Biella G, Panara C, Lucini V, Capsoni S, Fauteck J, Cozzi B, Fraschini F: Melatonin signal transduction and mechanism of action in the central nervous system: using the rabbit cortex as a model. Endocrinology 1992;130:2152-2159.

19 Igawa Y, Mattiasson A, Andersson KE: Effect of GABA-receptor stimulation and blockade on micturition in normal rats and rats with bladder outflow obstruction. J Urol 1993; 150:537-542.

20 Matsuta Y, Yusup A, Tanase K, Ishida H, Akino H, Yokoyama O: Melatonin increases bladder capacity via GABAergic system and decreases urine volume in rats. J Urol 2010; 184:386-391

21 Garcia JJ, Reiter RJ, Guerrero JM, Escames G, Yu BP, Oh CS, Munoz-Hoyos A: Melatonin prevents changes in microsomal membrane fluidity during induced lipid peroxidation. FEBS Lett 1997;408:297-300. 
22 Kilic E, Ozdemir YG, Bolay H, Kelestimur $\mathrm{H}$, Dalkara T: Pinealectomy aggravates and melatonin administration attenuates brain damage in focal ischemia. J Cereb Blood Flow Metab 1999;19:511-516.

23 Ross D: Glutathione, free radicals and chemotherapeutic agents. Mechanisms of free-radical induced toxicity and glutathione-dependent protection. Pharmacol Ther 1988;37:231-249.

24 Tan DX, Chen LD, Poeggeler B, Manchester LC, Reiter RJ: Melatonin: a potent, endogenous hydroxyl radical scavenger. Endocr J 1993;1:57-60.

25 Tan DX, Poeggeler B, Reiter RJ, Chen LD, Chen S, Manchester LC, Barlow-Walden LR: The pineal hormone melatonin inhibits DNA-adduct formation induced by the chemical carcinogen safrole in vivo. Cancer Lett 1993;70:65-71.

26 Sewerynek E, Melchiori D, Ortiz GG, Poeggeler B, Reiter RJ: Melatonin reduces $\mathrm{H} 2 \mathrm{O} 2$-induced lipid peroxidation in homogenates of different rat brain regions. J Pineal Res 1995;19:51-56.

27 Sewerynek E, Melchiorri D, Reiter RJ, Ortiz GG, Lewinski A: Lipopolysaccharide-induced hepatotoxicity is inhibited by the antioxidant melatonin. Eur J Pharmacol 1995; 293:327-334

28 Melchiorri D, Reiter RJ, Sewerynek E, Chen LD, Nistico G: Melatonin reduces kainate-induced lipid peroxidation in homogenates of different brain regions. FASEB J 1995;9: 1205-1210.

29 Reiter RJ, Tan DX, Manchester LC, Qi W: Biochemical reactivity of melatonin with reactive oxygen and nitrogen species. Cell Biochem Biophys 2001;34:237-256.

30 Allegra M, Reiter RJ, Tan DX, Gentile C, Tesoriere L, Livrea MA: The chemistry of melatonin's interaction with reactive species. J Pineal Res 2003;34:1-10.

31 Pieri C, Marra M, Moroni F, Recchioni R, Marcheselli F: Melatonin: a peroxyl radical scavenger more effective than vitamin E. Life Sci 1994;55:L271-L276.

32 Marshall KA, Reiter RJ, Poeggeler B, Aruoma OI, Halliwell B: Evaluation of the antioxidant activity of melatonin in vitro. Free Radic Biol Med 1996;21:307-315.

33 Gilad E, Cuzzocrea S, Zingarelli B, Salzman AL, Szabo C: Melatonin is a scavenger of peroxynitrite. Life Sci 1997;60:PL169-174.

34 Onur R, Tasdemir C, Seckin D, Ilhan N, Kutlu S, Akpolat N: Combined use of melatonin and terazosin restores bladder contractility in rabbits with partial outlet obstruction. Urology 2008;72:439-443.

35 Ersahin M, Özdemir Z, Özsavcı D, Akakın D, Yegen BC, Reiter RJ, Sener G: Melatonin treatment protects against spinal cord injury induced functional and biochemical changes in rat urinary bladder. J Pineal Res 2012; 52: 340-348.
36 Nomiya M, Burmeister DM, Sawada N, Campeau L, Zarifpour M, Yamaguchi O, Andersson KE: Effect of melatonin on chronic bladder-ischaemia-associated changes in rat bladder function. BJU Int 2013;112:E221230.

37 Shaw S, Herbert V, Colman N, Jayatilleke E: Efffect of ethanol-generated free radicals on gastric intrinsic factor and glutathione. Alcohol 1990;7:153-157.

38 Szabo S, Nagy L, Plebani M: Glutathione, protein sulfhydryls and cysteine proteases in gastric mucosal injury and protection. Clin Chim Acta 1992;206:95-105.

39 Reiter RJ, Tan DX, Osuna C, Gitto E: Actions of melatonin in the reduction of oxidative stress. J Biomed Sci 2000;7:444-458.

40 Paskaloglu K, Sener G, Kapucu C, Ayanoglu-Dülger G: Melatonin treatment protects against sepsis-induced functional and biochemical changes in rat ileum and urinary bladder. Life Sci 2004;74:1093-1104.

41 Andersson KE, de Groat WC, McVary KT, Lue TF, Maggi M, Roehrborn CG, Wyndaele JJ, Melby T, Viktrup L: Tadalafil for the treatment of lower urinary tract symptoms secondary to benign prostatic hyperplasia: pathophysiology and mechanism(s) of action. Neurourol Urodyn 2011;30:292-301.

42 Andersson KE, Arner A: Urinary bladder contraction and relaxation: physiology and pathophysiology. Physiol Rev 2004;84:935986.

$43 \mathrm{Yu} \mathrm{X}$, Kensler T: Nrf2 as a target for cancer chemoprevention. Mutat Res 2005;591:93102.

44 Surh YJ: NF-kappa B and Nrf2 as potential chemopreventive targets of some anti-inflammatory and antioxidative phytonutrients with anti-inflammatory and antioxidative activities. Asia Pac J Clin Nutr 2008;17(suppl 1):269-272.

45 Jin W, Wang H, Yan W, Xu L, Wang X, Zhao X, Yang X, Chen G, Ji Y: Disruption of Nrf2 enhances upregulation of nuclear factor-kappaB activity, proinflammatory cytokines, and intercellular adhesion molecule-1 in the brain after traumatic brain injury. Mediators Inflamm 2008;2008:725174.

46 Tripathi DN, Jena GB: Effect of melatonin on the expression of Nrf2 and NF-kappaB during cyclophosphamide-induced urinary bladder injury in rat. J Pineal Res 2010;48:324-331.

47 Hald T, Horn T: The human urinary bladder in ageing. Br J Urol 1998;82(suppl 1):59-64.

48 Gomez-Pinilla PJ, Gomez MF, Hedlund P, Swärd K, Hellstrand P, Camello PJ, Pozo MJ, Andersson KE: Effect of melatonin on age associated changes in Guinea pig bladder function. J Urol 2007;177:1558-1561.

49 Cardinali DP, Pevet P: Basic aspects of melatonin action. Sleep Med Rev 1998;2:175190.

50 Poeggeler B: Melatonin, aging, and age-related diseases: perspectives for prevention, intervention, and therapy. Endocrine 2005; 27:201-212.
51 Harman D: Free radical theory of aging. Mutat Res 1992;275:257-266.

52 Drake MJ, Mills IW, Noble JG: Melatonin pharmacotherapy for nocturia in men with benign prostatic enlargement. J Urol 2004; 171:1199-1202.

53 Paskaloglu K, Sener G, Kapucu C, Ayanoglu-Dulger G: Melatonin treatment protects against sepsis-induced functional and biochemical changes in rat ileum and urinary bladder. Life Sci 2004;74:1093-1104.

54 Gomez-Pinilla PJ, Gomez MF, Swärd K, Hedlund P, Hellstrand P, Camello PJ, Andersson KE, Pozo MJ: Melatonin restores impaired contractility in aged guinea pig urinary bladder. J Pineal Res 2008;44:416-425.

55 Dobrek L, Thor PJ: The influence of melatonin and agomelatine on urodynamic parameters in experimental overactive bladder model-preliminary results. Postepy Hig Med Dosw (Online) 2011;65:725-733.

56 Nomiya M, Sagawa K, Yazaki J, Takahashi N, Kushida N, Haga N, Aikawa K, Matsui T, Oka M, Fukui T, Andersson KE, Yamaguchi $\mathrm{O}$ : Increased bladder activity is associated with elevated oxidative stress markers and proinflammatory cytokines in a rat model of atherosclerosis-induced chronic bladder ischemia. Neurourol Urodyn 2012;31:185189.

57 Andersson KE, Arner A: Urinary bladder contraction and relaxation: physiology and pathophysiology. Physiol Rev 2004;84:935986

58 Zhang QH, Zhou ZS, Lu GS, Song B, Guo JX: Melatonin improves bladder symptoms and may ameliorate bladder damage via increasing HO-1 in rats. Inflammation. 2013; 36:651-657.

59 Cetinel S, Ercan F, Cikler E, Contuk G, Sener G: Protective effect of melatonin on water avoidance stress induced degeneration of the bladder. J Urol 2005;173:267-270.

60 Kwon KJ, Kim JN, Kim MK, Lee J, Ignarro LJ, Kim HJ, Shin CY, Han SH: Melatonin synergistically increases resveratrol-induced heme oxygenase- 1 expression through the inhibition of ubiquitin-dependent proteasome pathway: a possible role in neuroprotection. J Pineal Res 2011;50:110-123.

61 Matsuoka Y, Masuda H, Yokoyama M, Kihara $\mathrm{K}$ : Protective effects of heme oxygenase-1 against cyclophosphamide-induced haemorrhagic cystitis in rats. BJU Int 2007;100: 1402-1408.

62 Juszczak K, Ziomber A, Machowska A, Furgala A, Dobrek L, Wyczolkowski M, Thor PJ: The ameliorating effect of exogenous melatonin on urinary bladder function in hyperosmolar bladder overactivity and its influence on the autonomic nervous system activity. Acta Medica (Hradec Kralove) 2011;54:6368. 